\title{
PENSANDO LA PANDEMIA DESDE LA FILOSOFíA DE LA SALUd Una propuesta para la discusión
}

Thinking the Pandemic from the Philosophy of Health: a Proposal for Discussion

\author{
Amada Cesibel Ochoa Pineda ${ }^{1}$, CAyetano José Aranda Torres ${ }^{2}$ \\ ${ }^{1}$ Universidad del Azuay, Ecuador \\ ${ }^{2}$ Universidad de Almería, España
}

\begin{tabular}{|c|c|}
\hline KEY WORDS & ABSTRACT \\
\hline Philosophy & This essay, which is part of a health philosophy project, deals with the \\
\hline Health & impossibility of understanding SARC-Cov2, and the rest of nature, if we \\
\hline SARS-CoV2 & are not able to understand the human sense of knowledge and science, \\
\hline Epistemology & and the socio-cultural conditions of technological civilization and \\
\hline Ethic & globalized life, without which the pandemic would not have been possible \\
\hline Liberty & or, at least, its effects would have been mitigated and located in space / \\
\hline Responsibility & $\begin{array}{l}\text { time. It concludes with the need to make an ethical approach in relation } \\
\text { to freedom and responsibility in the era of globalization. }\end{array}$ \\
\hline
\end{tabular}

\begin{tabular}{ll}
\hline PALABRAS CLAVE & RESUMEN \\
\cline { 3 - 3 } $\begin{array}{l}\text { Filosofía } \\
\text { Salud }\end{array}$ & $\begin{array}{l}\text { El presente ensayo, que se enmarca en un proyecto de filosofía de la } \\
\text { SARS-CoV2 }\end{array}$ \\
Epistemología trata la imposibilidad de entender el SARC-Cov2, y el resto de la \\
Ética & saber y la ciencia, y las condiciones socio-culturales de la civilización \\
Libertad & tecnológica y la vida mundializada, sin las que la pandemia no hubiese \\
Responsabilidad & sido posible o, al menos, sus efectos habrían sido atenuados y localizados \\
& en el espacio/tiempo. Se concluye con la necesidad de hacer un \\
& planteamiento ético en relación con la libertad y la responsabilidad en la \\
& era de la globalización.
\end{tabular}

Recibido: 01/06/2020

Aceptado: 04/01/2021

\section{GLOBAL KNOWLEDGE}




\section{Pandemia y filosofía de la salud}

ostiene Kant, en una importante nota a la - Crítica de la razón pura, que la razón Wumana tiene el extraño y singular destino de verse agobiada por no poder dejar de plantearse de modo inexorable ciertos interrogantes, para los que no tiene capacidad de respuesta, digamos científica, pero que son exigidos por la propia naturaleza de la razón (Kant, 2007). Estos interrogantes tienen que ver fundamentalmente con la libertad humana, que no podemos saber qué es, pero que la necesitamos como postulado, si los humanos queremos pensar nuestras acciones, como producto de seres libres, racionales y responsables de sus actos (Kant, 2000). Todo parece indicar que el SARS-CoV2 amenaza nuestra libertad y pone en cuestión el tema de la responsabilidad, en tres registros básicos, el de la ciencia, el de los individuos singulares, y el de los poderes públicos. Ni que decir tiene que, en los tres ámbitos aludidos, pensamos con Kant que se da una causalidad por razón de la libertad, más acá y más allá de la causalidad de la naturaleza, tomada la causalidad libre o humana como un factum de la razón (Kant, 2000).

Desde el comienzo de la crisis sanitaria, desencadenada por el virus antedicho, los que ejercemos el pensamiento de modo reflexivo y crítico nos hemos planteado las mismas cuestiones que en otros casos, como el VIH o el Ébola se hacían, a saber, qué poder tiene la naturaleza sobre la humanidad y qué recursos tiene ésta para vencer, en este caso, a una microscópica partícula. Muchas voces se escuchan arguyendo que sólo el trabajo y los resultados de la ciencia, junto a la responsabilidad individual son suficientes para afrontar y resolver, si bien no de manera radical y definitiva, la pandemia actual (Pita, 2020). Nuestra posición no puede ser menos que matizar sustantivamente la expresada por Pita, cuando no se incluye, entre los medios para hacer frente a la situación, las decisiones de los poderes públicos, sometidos a la tensión de los dictámenes científicos $\mathrm{y}$, por otro lado, la influencia de la opinión pública o publicada, sea cual sea el medio en el que ésta se expresa.
Por un lado, la microbiología conoce relativamente bien la realidad concreta que motiva nuestra reflexión. Apenas una molécula de ARN y unas proteínas; progresa si los humanos la transmitimos; de lo contrario, apenas si sería objeto de una curiosidad tan lujosa como superflua. ¿Responsabilidad individual en la trasmisión? Sin duda que sí, pero también colectiva, de los poderes públicos, desde la conducta de los adultos y discentes que son imitadas por los más pequeños, y de todos los gobiernos del mundo, de y en los que cabe suponer la voluntad y el deseo ferviente de acabar con la epidemia. Por otro lado, nos encontramos con la epidemiología, que se basa en la estadística, en muchos casos, de tipo muestral. Sin duda sus resultados son probabilísticos, incluso de alta probabilidad, pero nunca exactos, con la exactitud de la evidencia científica que, caracteriza a las ciencias duras, como la matemática, la física o la biología. El carácter aproximativo de los estudios epidemiológicos, aunque ofrezca altas probabilidades de acierto, plantea a los que han de tomar decisiones que el recurso a ella sea o pueda ser el único argumento para dar un cierto barniz científico a sus decretos o providencias (confinamiento, desescalada, vuelta a la normalidad, política de semáforos, y un largo etcétera), en especial, las referidas al correcto uso de los recursos sanitarios, siempre costosos y nunca suficientes, en cada país del globo.

El problema, tal y como lo consideramos los autores de este trabajo, es que el criterio de los científicos es claramente insuficiente para afrontar la presente crisis, en muchos casos, porque sabiendo mucho de virus y pandemias, carecen de la suficiente humildad o, dicho de otro modo, sus actitudes y opiniones derivan en la soberbia de creerse investidos de un poder absoluto e in-finito sobre la naturaleza, cuando la naturaleza misma, incluida la humana como una pequeña parte, es el elemento relativo y el componente finito de la realidad. Visto desde determinado punto de vista, estamos ante un organismo inferior, dicho sin ninguna arrogancia, que causa estragos por razón del modo humano de habitar la tierra. Resulta ser un expediente sencillo y fácil poner énfasis exclusivamente en la morbilidad y mortalidad del virus, y no 
reparar en la manera singular que los humanos hemos adoptado de vivir en nuestro planeta, que hoy como ayer resulta decisiva para el contagio.

La "filosofía de la salud", postulada por los autores de este trabajo y sometida a la benevolencia de los lectores de la Revista Internacional de Humanidades Médicas, considera que la salud, como responsabilidad de todos y cada uno de los humanos, tiene que ver con el cuidado de sí como práctica de la libertad, tal y como ha sido propuesto por Michel Foucault (Foucault, 1999), y con todas aquellas prácticas y tareas relacionadas con la salud, que nos conciernen como humanos racionales, en contra, en cierto modo de la enajenación de la salud, que es la tendencia dominante en los sistemas sanitarios, sean públicos o privados (Gadamer, 1993). Nuestra consideración programática del concepto de salud, que sometemos a la consideración de toda opinión más experta, formada e informada que la nuestra, tiene que ver con lo siguiente. Si es cierto que "la salud exige un estado de armonía con el medio social y con el medio natural" (Gadamer, 1993, 147), la sanidad tiene que ver con la curación de las enfermedades y el restablecimiento del bienestar corporal y mental, mediante su diagnóstico y tratamiento, pero la salud es una dimensión del vivir humano que va más allá de la mera ausencia de enfermedad. Ésta deteriora a aquella, pero hay sanos sin salud, y también menudean enfermos que aparentan salud. De ahí nuestra definición tentativa, según la cual la salud es la fuerza de oponer resistencia a las enfermedades, la potencia y energía para no estar enfermos y en forma, al tiempo que el estado de ánimo que permite desarrollar las actividades que podamos proponernos a nosotros mismos como formando parte de nuestro proyecto de vida. Todas estas dimensiones referidas han de articularse en instituciones sociales que fomenten la salud como bien público. A nuestro modo de ver, un rasgo esencial y no menor de la libertad en el momento presente, que se ha constituido en principio básico de la ética de la salud, tiene que ver con el cuidado de sí, que abarca un amplio y extenso ámbito de influencia en la vida humana (Castro Orellana, 2008).

El auténtico y más profundo problema que tiene plantado la humanidad, al margen del prioritario de preservar la salud pública, consiste en plantear la relación de la humanidad con el resto de la naturaleza, por así decirlo no humana, a fin de ensayar y promover una actitud no sólo de respeto sino de serena meditación sobre los efectos de los modos de vida sobre el medio natural. No es de ninguna manera casual que el SARS-CoV2 se hay originado en China, país cuyo desarrollo capitalista no contempla casi ninguna restricción, ni ética ni política, ni en el respeto a la democracia y los derechos humanos ni, en fin, en el acatamiento de los límites y sostenibilidad de los recursos naturales y medioambientales. Aún sigue vigente la pregunta de raíz socrática sobre cómo el conocimiento cosmológico, de la phýsis en su conjunto, puede configurarse de manera que corresponda a la auto-comprensión de la humanidad, en el fundamental propósito de ésta de realizar el bien común. Esta pregunta de Sócrates está en el origen de la metafísica y sigue siendo una de las preguntas clave de la existencia humana (Gadamer, 2002).

\section{La humanidad y la naturaleza no humana}

El auténtico problema actual, al margen del urgente de preservar la salud pública a nivel mundial, consiste en la relación de los seres humanos con la naturaleza, de nuestra actitud invasiva y petulante ante ella, de la explotación sin límites de sus recursos y, en definitiva, del intento de someterla sin restricción para determinados fines, que se mantienen preservados de toda crítica. El ejemplo del SARS.Cov2, un minúsculo cachito de naturaleza, y del consecuente Covid-19, es muy elocuente. En tanto no encontramos la forma de su eliminación, o de atenuar su morbilidad, no somos capaces de mirarnos a nosotros mismos, para aclarar las causas culturales, sociales, económicas y políticas de la pandemia. El problema no es tanto la naturaleza, con su innegable presión ejercida sobre la parte humana de ella; sin duda ese empuje nos ha obligado a la humanidad a evolucionar y, en buena medida, para bien. Lo grave es ese segmento de la naturaleza que cree ser superior o privilegiado sobre el resto, por disponer del conocimiento de los fenómenos naturales, porque ha vinculado el saber a un 
modo de vida, para el que, como decía Tarde a comienzos del siglo XX, el apogeo de la prosperidad humana parecía logrado (Tarde, 2002). Desde hace siglos, el habitar humano la tierra no se acomoda a los límites que dis-pone la naturaleza, tomada en su conjunto, y que hoy englobamos en el término sostenibilidad. No hay dos gramáticas, la natural y la humana, sino sólo una, la que es producto del estímulo y condicionamiento natural sobre el ser y el hacer de todos los seres, tanto orgánicos como inorgánicos, y que obliga a la adaptación al medio. Nada nos asegura que la relación de los humanos con la naturaleza se haya pensado con todo rigor $\mathrm{y}$ profundidad, a pesar de, o precisamente por, el hecho de la ciencia y la tecnología modernas, que ocultan, solapan y velan aspectos esenciales de la mentada relación. Puede ser no solo interesante sino muy productivo, como veremos en seguida, reparar el carácter condicionante y determinante de los hechos naturales, en este caso un virus, y de nuestro conocimiento de ellos.

La naturaleza no se encuentra tan sólo en los laboratorios que trabajan afanosamente para lograr una vacuna contra el virus, sino también en el tipo de comunidad, que los griegos llamaron pólis, que los alberga y financia. Conceptualmente todo depende de considerar y tener en cuenta la noción de limitación, en el sentido de que no existe nada en el universo mundo que no se encuentre determinado por la categoría de límite, en la acepción según la cual, en el fondo, no hay otros límites que los humanos (Trías, 1991; Trías, 2000). Cualquier parte o partícula de la naturaleza no es sólo un objeto de laboratorio sino también algo que posee un régimen propio; éste muestra que no se identifica sin residuo o completamente con lo que de ella saben los científicos. La cosa de la que hablamos procede del mundo inorgánico, no tiene vida propia, pero es nociva para el organismo humano pues se adhiere y ataca a determinadas células. No se refiere de manera genérica a lo humano, sino a un determinado modo de entender la vida humana en la actualidad.

Los lectores de la Revista Internacional de Humanidades Médicas saben que la historia de la medicina nos ha familiarizado con la tesis de que las enfermedades son el producto de una intrusión de la vida inorgánica en la orgánica, tesis parcialmente desmentida por el descubrimiento de las enfermedades autoinmunes. Pero, detengámonos por un momento en la idea de que algo amenaza el organismo humano, fuera del cual es irrelevante y el jabón de uso común lo destruye. Afortunadamente para el género humano, éste ha dispuesto tarde o temprano de la tecnología para acabar con la amenaza. Pero lo decisivo en este momento, a la vez que desafortunado, resulta ser que las amenazas que nos acompañan desde nuestro nacimiento filogenético y ontogenético, las hemos llegado a ignorar en aras de una felicidad basada en el desconocimiento y la imprudencia. Vivir como si no existieran los peligros tiene que ver con un modo de vida humana que pre-supone, en este caso equivocadamente, o bien que somos en cierto modo invulnerables, o bien que, si no estamos libres de amenazas, podemos superarlas y vencerlas con mayor o menor dificultad, con mayor o menor costo social. El error estriba en creer que el dispositivo de la ciencia y la tecnología, que parece que todo lo puede, nos oculta su propia limitación. Puede lo que puede o lo que los científicos y tecnólogos nos hacen creer que pueden. En la actual tesitura, el interrogante es claro: ¿puede la cienciatecnología ser el único consuelo y esperanza de la humanidad amenazada por la pandemia? Nuestra posición, desde la filosofía de la salud, es que aún necesitamos algo tan importante e indispensable como pensar la finitud y falibilidad de toda la naturaleza como factor determinante. Y, lo que es más importante, reflexionar en la circunstancia según la cual el resto de la naturaleza, digamos no humana, no es ni puede ser una bodega, estantería o despensa, donde se encuentran almacenados bienes de todo tipo, a disposición arbitraria de la humanidad. Los virus son el ejemplo de una naturaleza que no está dominada ni se deja dominar fácilmente por los seres humanos. La naturaleza en su conjunto, incluida la humana, posee un resto in-dominable, al que nunca podemos reducir ni siquiera en un futuro previsible.

Los virus son partículas de ARN/ADN con una envoltura de proteínas. No se reproducen por sí 
mismos sino infectando células de quien los acoge como huésped, trasladándose de un hospedaje a otro $y$, por fin, evitando ser eliminados por el sistema inmunológico de quien les proporciona hospitalidad. Determinadas células, no sólo las humanas de los sistemas respiratorio, circulatorio, reproductivo, etcétera, dejan de reproducirse y producen virus en lugar de células. En definitiva, los virus son parásitos inertes que pertenecen a la célula como unidad básica de la vida, que muestra que la interacción de lo orgánico con lo inorgánico es un proceso constante y permanente. Para decirlo de modo sencillo, los virus son toxinas, tósigos para la vida animal, por su dinámica de supervivencia, a costa de las células, tal como parece que hacemos los seres humanos a costa de otras formas de vida. Podemos llegar a decir que donde hay un organismo vivo, estamos ante la posibilidad de una infección por agentes patógenos. Si éstos necesitan a las células vivas es para causarles un mal que acaba con ellas. La comunidad científica llega a plantearse si son organismos vivos, aunque sí es seguro que rondan y limitan la vida, a modo de parásitos que amenazan la salud humana. De ahí nuestro postulado, esencial a toda consideración reflexiva de la salud, de que los virus tienen individualidad propia, y que no es posible separar esa pequeña parte de la naturaleza del resto, porque la distinción entre la naturaleza humana y la no humana es una convención que resulta epistémicamente irrelevante.

En general, los humanos nos hemos tomado a nosotros mismos en nuestras acciones como fines a los que subordinar el resto de la biosfera. Lo razonable de esta visión que, al menos procede del mundo de los antiguos griegos, sigue siendo válido para todo peligro que ponga en riesgo a la propia humanidad. Pero seguimos sin pensar la índole del "fin", que en alemán se dice Zweck, para indicar que se refiere al propósito que introducimos como télos de nuestras acciones, en especial frente a los objetos de la naturaleza (Hegel, 1997). En concreto, no hemos pensando con suficiente detenimiento los fines referidos a lo práctico, es decir, cuando aludimos a todo aquello que emprendemos con vistas a la supervivencia y, muy especialmente, no tanto para entender el esfuerzo por sobrevivir en condiciones extremas, cuanto sencillamente tratamos de vivir en las condiciones superiores propias de la cultura humana repleta de artificios. No somos conscientes que arriesgamos el futuro de una parte de la humanidad, la más vulnerable, cuando surge una amenaza, que discrimina poderosamente en sus efectos, hasta el punto de que parece que nos induce a pensar que algo hemos de sacrificar para vencer esa amenaza, y ese algo deber ser valioso. No es tanto la parte de la humanidad más vulnerable que el resto, sino toda forma de humanidad, porque su naturaleza dice relación esencial con la vulnerabilidad de la especie, que puede estar amenazada en su supervivencia.

Pero volvamos por un momento a lo que con Hegel llamamos "el punto de vista teleológico finito" (Hegel, 1997), que se resuelve en tomar el objeto como mero material para la realización de nuestros fines, que no supone ningún género de materialidad específica, sino todo lo que se requiere para fabricar los útiles, desde el cuero para un par de zapatos hasta la sílice y el coltán para un celular. Desde este punto de vista cabe preguntarse si la naturaleza contiene en sí misma un fin absolutamente último, que implica que al virus no se le reconoce la posibilidad de sobrevivir a nuestra costa, y que toda realidad finita está subordinada a los fines humanos que libremente se plantea nuestra especie, lo que también puede ser objeto de debate.

Pero todavía el reto de la pandemia requiere ir más allá de ese punto de vista teleológico finito y sus dos derivaciones. Proponemos al lector de esta revista una sugerencia especulativa, adjetivo que se deriva del latín speculum, que no es otra cosa, como en el caso del instrumento clínico, que un punto de vista más elevado y preciso sobre los fenómenos observables en general. Se trata de pensar como posible, más allá y más acá del saber científico, propio del conocimiento finito de las cosas finitas, que hay otros conceptos que tratan de pensar la naturaleza a partir y beneficiándose de los resultados de la ciencia. El que las ciencias naturales trabajen con objetos empíricos y experimentales, y que busquen leyes de validez universal, no las convierte en la únicas que hacen posible saber sobre la naturaleza. El problema que planteamos emerge cuando las propias ciencias consideran la 
naturaleza como una organización, que es una forma de verla como una totalidad orgánica. Dicho con otras palabras, nuestro saber común y el saber científico propenden a ver la naturaleza como un todo orgánico con finalidad propia, como un organismo que busca y pretende como finalidad crecer y multiplicarse, sobrevivir incluso a pesar de un entorno hostil. El organicismo propio de la ciencia de la naturaleza debe ser repensado porque tiene que ver esencialmente con la relación de interacción de la especie humana con su entorno natural y social. Expresado de otra manera, nuestra relación con la naturaleza toda, está condicionada por una mediación digamos sociopolítica que, como ha mostrado Hegel, determina la manera de considerar la propia naturaleza (Aranda Torres, 1992).

La reflexión que incoamos desde una filosofía de la salud, se hace a partir de tomar los fenómenos físicos $\mathrm{y}$, por extensión, los biológicos, como la condición y el origen del pensar todas las cosas mundanas, como lo atestigua la historia de la filosofía desde Tales de Mileto. Apostamos por la tesis fuerte de que la finalidad aumenta nuestro conocimiento de la naturaleza (Spaemann, 1991). En este sentido, todos los objetos naturales se nos aparecen como algo ajeno y otro en relación con el pensamiento y la inteligencia, pero esta apreciación inicial es contradictoria. Lo otro es lo otro de nosotros mismos, lo que hemos objetivado para mejor conocerlo y dominarlo. Sin la finalidad de dominio no hay conocimiento. La exterioridad de una partícula muy pequeña, que la microbiología se esfuerza en conocer su estructura y dinámica, sería el ejemplo de un dispositivo para su estudio, control y eventual desactivación mediante una vacuna. Si todos los virus pertenecen a los seres vivos, la filosofía entiende que estamos ante una exterioridad mutua $y$ recíproca, pues, si nos situáramos en el punto de vista de la naturaleza, veremos que el sentido $y$, por qué no, la finalidad de un virus es existir en y para otro.

Las anteriores consideraciones nos llevan al núcleo duro de nuestras consideraciones en este trabajo. Todo se resume en repensar, si quiera brevemente, en las dos características conceptuales de los seres naturales, entre los que nos contamos nosotros los humanos: necesidad y contingencia. Todo lo que existe en el universo mundo es necesario y contingente. Necesario porque, a diferencia de otras realidades, todos los seres forman parte del factum de lo dado, de esa realidad externa entre sí, que no es posible borrar o eliminar a capricho. Contingente porque como seres finitos no somos eternos; nacemos y perecemos $\mathrm{y}$, en la medida de que toda realidad es individual, es objeto y fin de la vida, que convierte a lo inorgánico y lo orgánico en prescindible, innecesario y perecedero.

Hay una expresión hegeliana, "contradicción no resuelta" para referirse a la naturaleza (Hegel, 1997, 306-308), que nos puede ser de alguna utilidad para concebir la pandemia desde el punto de vista de las humanidades médicas. En primer término, porque hasta que no ingresemos en el modo de ser humano, configurado por los que vivimos en sociedad, mientras no pensemos la naturaleza espiritual de la humanidad, no podemos entender en verdad la naturaleza, digamos no humana. No nos referimos a que lo natural sea puesto o inventado por lo social, sino a que lo socio-comunitario crea a su vez los dispositivos científicos y tecnológicos que convierten a la naturaleza en objeto de estudio y libre disposición, siempre de acuerdo con las pautas e intereses de la historia humana.

En segundo lugar, el planteamiento se hace más explícito cuando pensamos la naturaleza y sus objetos desde la única categoría que los hace posibles, la categoría de vida, pues lo inorgánico, en la medida en que carece de vida, si bien no de diseño, tiene un escaso interés humano. Sólo porque partes ínfimas de materia se relacionan con la vida $y$, en especial con la humana, han sido objeto de asombro y admiración, ha sido posible su estudio y conocimiento preciso, y se han convertido en una "contradicción no resuelta". Por esto, el corolario de estas consideraciones sobre la polaridad naturaleza/vida humana, consiste en formular la pregunta de cómo el tipo de vida humana que representa la humanidad presente hace posible la pandemia, porque sólo el saber humanístico puede resolver el interrogante de naturaleza ética que nos plantea el SARS-Cov2 (Žižek, 2020a). Las humanidades están concernidas por la salud en la misma medida que las ciencias médicas; éstas desde los 
avances que supone la biomedicina; aquellas porque la salud ha sido un objeto privilegiado de la reflexión filosófica sobre la vida humana en todas sus dimensiones.

\section{Consecuencias ético-políticas}

Cuando la filosofía pone especial énfasis en la contingencia de todo lo natural, no deben sorprender los atinados diagnósticos coetáneos, según los cuales, dado que los datos estadísticos y la mucha información carecen de fuerza simbólica y vinculante, y están ayunos de capacidad de ser reconocidos por la mayoría, estamos ante una pérdida de la comunidad humana, a costa de una cierta comunicación ilimitada de los datos (Byung-Chul Han, 2020a; Byung-Chul Han, 2020b; Žižek, 2020b). Aquí radica tal vez la hodierna ausencia de fundamento del habitar humano la tierra. El modo humano de poblar y morar la tierra se denomina hábito o costumbre, y éste es el terreno o ámbito de la ética. No podemos aceptar de ninguna manera que lo ético diga relación exclusiva a la formación del carácter, como lo pretenden algunos planteamientos muy en boga actualmente. Desde Kant sabemos y podemos estar de acuerdo sin reserva con que la ética tiene por sujeto y objeto la libertad humana, esto es, ella es el saber sobre y por la libertad (Kant, 2000; 2007). Incluso podemos afirmar que el verdadero sentido del saber filosófico es el de saber y entender de la libertad de los seres humanos, no sólo individual sino también de la establecida institucionalmente, y reconocida en usos y costumbres. Pero la humana conditio se caracteriza por una fragilidad y caducidad extremas: somos libres pero frágiles y caducos o, tal vez por ser de este modo aspiramos a ser libres (Butler, 2020).

Desde el origen de nuestra cultura occidental, en la época de los antiguos griegos, hemos defendido que lo bueno y lo justo también dicen relación directa con la libertad, tomada como la energía que pone en marcha el pensamiento de seres que viven con y en la naturaleza entorno, e insertos en sociedades organizadas, cuya condición ética tiene que ver tanto con el carácter de cada uno como con las normas y leyes que educan el carácter y ordenan la convivencia. Es un lugar común pensar que la totalidad del género humano quiere dar, en la presente coyuntura de la pandemia, un paso hacia la sensatez y la cordura, frente a conductas irresponsables y de riesgo, teniendo en cuenta que no puede ser excluido un cuestionamiento, todo lo radical que sea posible de los usos, costumbre y modos de vida globalizados. Nuestra apuesta cree firmemente que la actual crisis sanitaria representa un antes y un después en los hábitos sociales, con su directa repercusión en la antedicha educación del carácter y de la ciudadanía.

Por extraordinaria e inusual que parezca la pandemia que sufrimos y las medidas precisas para superarla, que a los apocalípticos les parecen cuanto menos terribles, si lo pensamos bien y recapacitamos sobre la situación presente, veremos que no es una novedad en el transcurso histórico de la humanidad, porque no es la primera ni será la última. Lo que es nuevo es la hasta cierto punto confianza en nuestra humanidad como género que resuelve a la larga todos sus problemas, promovida por la ideología cientifista, que promete, en uno u otro sentido, soluciones radicales; ella ha generado el optimismo generalizado en soluciones exclusivamente bio-médicas, desde el respirador a la vacuna, cuando el asunto tiene mucho que ver con nuestros modos de vida. En su visión apocalíptica y visionaria de comienzos de la centuria pasada, rara pero no tanto a la vista de lo acontecido en la historia del último siglo, Gabriel Tarde advierte del peligro de la completa eliminación de la naturaleza con la sola excepción del ser humano. Con ella, la sociedad habría logrado su objetivo de sustraerse al medio natural, en definitiva, la sociedad habría conseguido ser autónoma de cualquier influencia natural (Tarde, 2001).

El problema fundamental al que hemos de hacer frente consiste en hacer compatible la necesidad natural y ciega de la naturaleza, tanto orgánica como inorgánica, con la libertad que la humanidad se arroga frente a las leyes inflexibles de aquella. Este conflicto resulta ser aparente para Kant, que lo desarrolla en la tercera antinomia de la Crítica de la razón pura (Kant, 2007), para encontrar una solución, si bien no exenta de dificultades. Para resolver éstas es preciso tener en cuenta dos características de los 
seres naturales que aún no hemos pensado suficientemente: son concretos y puntuales, y contingentes. En lo referente a nuestra naturaleza, si consideramos las condiciones del saber científico y nuestra capacidad de acción, Kant saldó el conflicto postulando en el ser humano una facultad de actual por la libertad $y$, de este modo, ser causa de fenómenos fehacientemente verificables como hechos, cuya facticidad obedece, no obstante, a una serie de causas naturales, como puede ser la escritura de este artículo por sus autores (Kant, 2007).

Por otra parte, vivir con miedo es natural, pertenece a la condición humana, siempre que no nos paralice, como ocurre en el caso de algunos personajes de E. A. Poe. El autor norteamericano juega con el miedo natural humano, sin recurrir a la hipérbole visual que caracteriza nuestro tiempo, que conmociona al lector/espectador con imágenes sobresaturadas de emociones catastróficas (Aranda Torres, 2015). Aún nos queda un margen de confianza, derivado de la capacidad de reacción individual y colectiva ante un acontecimiento pasmoso, asombro que, no paraliza la dinámica cognoscitiva, y sí es la condición de la reacción ante y frente al mismo. En este sentido, la serenidad es un componente básico de la ética que necesitamos para el presente y el futuro; implica la confianza en la ciencia para resolver determinados problemas humanos, pero no todos. De la misma manera que confiamos en los cirujanos en el quirófano, los pilotos de aeronaves o los conductores de buses, debemos confiar también en los políticos, a los que podemos investir o revocar democráticamente. La respuesta serena no supone dejadez, desidia o negligencia alguna, sino algo mucho más importante, deja oír el nómos de la tierra, como la acogedora y huésped universal de la humanidad. La serenidad se opone al desenfreno, impaciencia y carácter incondicionado de la perspectiva científicotécnica, pero el ideal de serenidad, que trata de dejar atrás el super-predominio del querer desatado y el decisionismo, no niega el progreso técnico (Heidegger, 2002).

La ética para hacer frente a esta pandemia y las que a buen seguro vendrán en el futuro debe cuestionar la enorme aceleración a la que está sometida la civilización planetaria, y considerar no sólo las consecuencias benefactoras de la transmisión digital de la información, sino también las posibilidades de contagio e infección vírica, de manera también acelerada. Nadie ignora la naturaleza y función de los virus, pero nadie imaginaba sus consecuencias, por muy previsible que fuese su morbilidad, porque todos hemos ignorado o desconocido hasta ahora la realidad de la vida humana planetaria y sus consecuencias para la salud. El vivir en común actual es un producto condicionado hasta tal punto por la tecnología, que determina muchos aspectos de nuestra cotidianidad, también sentimientos y afectos, y que lleva aparejado una crédula fe optimista, tanto en el progreso infinito en todos los órdenes, cuanto, lo que es grave, en la invulnerabilidad de la naturaleza humana, que olvida la extrema fragilidad que acompaña a la grandeza humana. La ética planetaria que este rato se impone multi-lateralmente, se caracteriza por un optimismo radical, hijo legítimo de la tecnología mecánica, ejemplificada en las TIC. La única alternativa que nos está propuesta a los humanos en estos tiempos de penuria e indigencia, sería una ética que tomase la fragilidad como factum, y que se enderezase a pensar que somos seres limitados con vocación de cuidadores. Para aprender a ser cuidadores hemos de empezar por cuidar de nosotros mismos. Para eso, es preciso volver al asombro (thaumázein) de los griegos como procedimiento metódico frente a la actitud cartesiana, impresa en la ciencia moderna, con su énfasis en la planificación y prevención, que conjura a toda costa esa libre actitud admirativa (Descartes, 2006). El asombro-admiración por la naturaleza es lo anterior y previo, la condición vital fundamental, de la actitud invasiva $y$ transformadora, propia de la perspectiva científico y tecnológica. El dictum de Heidegger, según el cual la ciencia no piensa, quiere darnos a entender que la tecnología actual es incapaz de proporcionar la medida precisa para el habitar humano la tierra (Heidegger, 2007). Esa medida incluye, ante todo $\mathrm{y}$, sobre todo, una ética del cuidado y los cuidados. La vocación de cuidador y cuidadora tiene que abrir paso a la actividad de los cuidados múltiples, que no es una actitud solamente profesional. 
La pandemia nos impulsa a pensar cómo es en realidad la historia humana, y que necesidad la caracteriza, si la natural o la derivada de la libertad, justo lo que el historicismo del siglo XIX puso en primer plano de actualidad, y a lo que definió como el peso específico del pasado sobre lo que los individuos pensamos y hacemos. Pero no es menos cierto que la influencia del pasado se encuentra hoy sobre-determinada por el desarrollo científico-tecnológico, que concreta y precisa toda actividad humana en el presente (Álvarez Gómez, 2007). Ni que decir tiene que el factor de mayor impacto en la vida humana, para lo bueno y lo malo, es la ciencia con su poder descubridor y la técnica con su poder innovador. De esto se deduce que la humanidad se encuentra en la circunstancia presente, terrible si se mira por el lado de cierta consecuencias medioambientales, de tener que asumir no solo aquello de lo que es agente y responsable de modo inmediato y directo, sino, en general, de todo lo que, de manera imprevista o no planeada, le pueda acontecer, todo lo que nos induce a presentir un no menos aciago futuro quizá dramático, sin que, en el fondo, tras el destino se oculte la dimensión de espanto, en el sentido griego de lo deínotaton, de la acción humana.

Todo lo anteriormente expuesto nos pone sobre aviso del peso y calado de la magnitud ética de la vida humana: la libertad como condición y resultado de la vida, en el sentido de que, por muy condicionadas que puedan estar nuestras decisiones, en ellas se encuentra depositado un componente voluntariamente libre, y de responsabilidad que, incluso ante el desconocimiento posible de los efectos de nuestras acciones, no nos exime de tener que responder de ellas, tanto de las pasadas como de las presentes. La humanidad no deja ni dejará de ser responsable de sus actos, incluso cuando no se tome en consideración el principio que debería regular sus acciones: el principio de la phrónesis, que ahora más que nunca entendemos como prudencia, sensatez y buen sentido. Definimos la sabiduría prudencial como la excelencia que ha de presidir nuestras vidas ahora y el futuro, y a la que debemos encaminar nuestras acciones, tanto individuales como colectivas.

Una ética presidida por la acción prudente tiene que plantearse el desafío que nos suscita concebir una comunidad de egos, eso sí, bien interconectada por las redes sociales, pero con vínculos flexibles y débiles, con relaciones efímeras y caedizas, carentes de compromiso. Por otro lado, la libre movilidad ciudadana y la progresiva eliminación de las fronteras nos hacen vivir con y en la ilusión de que todo el planeta se encuentra a nuestra disposición, a la mano, sin esfuerzo ni contrapartida alguna. La globalización, con su libérrima circulación de capitales, mercancías e informaciones, nos vela y oculta que también podemos intercambiar huéspedes indeseados, humanos y de los otros. No deja de ser cierto que hemos olvidado lo local, lo patrio, lo hogareño y entrañable, algo que parece imponer el confinamiento (de nuevo, la malhadada raíz "fin"), que nos recuerda nuestra finitud y limitación, que seguimos existiendo, paradójicamente, gracias a la seguridad y protección de nuestros hogares.

En la frase de Carlos Fuentes, "no hay globalidad que valga sin localidad que sirva" (Fuentes, 1999), no podemos entender una empecinada actitud anti-progreso y conservadora; antes bien, señala y despeja el profundo pensamiento de lo local, los lugares en los todos y cada uno de nosotros nos ubicamos y habitamos, pensemos por un momento en Wuhan, que no sólo existen, sino que tienen una proyección e interacción planetaria entre ellos. De ahí que, entre otras, nuestra tarea como humanidad en su conjunto, sea volver a pensar el lugar, demorarse en él, aprender a construirlo y habitarlo, respetando sus exigencias de seguir existiendo y siendo esencial para la vida humana, en la medida en que así atestiguamos que somos hijos e hijas indefensos de la tierra como lugar, grávidos de finitud y limitación. Los nativos y asimilados de la era digital y la mundialización parecen vivir instalados en los no-lugares, en los espacios digitales en los que hasta el sexo es virtual (Ochoa Pineda, Aranda Torres, 2019). Frente y contra todo confín, que existe y seguirá existiendo, hemos de ser simbióticos con lo hogareño y lugareño, y, muy especialmente con la hospitalidad.

Heterogeneidad, hibridación y mestizaje de lo propio y lo extraño, de lo indígena y lo foráneo, de lo hogareño y lo extranjero, de lo patrio y lo apátrida, no son sino componentes esenciales de 
la ética que el presente precisa y demanda, que también deberá asumir la perspectiva cosmopolita, tal y como Kant lo diagnostico a finales del siglo XVIII (Kant, 2006). No está de más y parece oportuno recordar que para Hegel, que pasa por ser de manera equivocada, el mentor del estatalismo y el nacionalismo alemán, los inicios de la cultura y la civilización europeas, en la Grecia clásica, modelo por excelencia para el pensador germano, tienen que ver con la llegada de los extranjeros, cuyo ejemplo más conspicuo es Aristóteles, un macedón que prosperó y triunfó en Atenas. Porque, en definitiva, la humanidad y estas humanidades concernidas con y por la salud, para promoverla y promocionarla, tomada como poder espiritual, nacen y crecen consumando la diferencia y lo distinto, lo ajeno y foráneo, para construir un mundo sin fronteras, pero atento a la localidad en la que todos los seres humanos estamos enraizados, y cuya carencia ocasiona la apatricidad, una de las peores lacras de nuestro tiempo.

Pero aún más importante para la ética presente y futura es la necesidad de considerar que el resto de la naturaleza no humana no es un fondo a disposición o almacén, de uso arbitrario para la humanidad. Este virus es el ejemplo para que, de modo paradójico, aprendamos a respetar la naturaleza, que creemos dominable y dominada, como se respeta a un enemigo, cuya principal virtud es hacerte crecer y hacerte más fuerte. La naturaleza en su conjunto, incluida claro está la humana, detenta un resto o fondo indominable, y así debe seguir siendo para el bien de todos, para que sigan existiendo estímulos para el esfuerzo y la excelencia humanos.

Para definir y precisar de modo conclusivo las consecuencias éticas implementadas por la actual pandemia, vamos a seguir el planteamiento de Paul Ricoeur, según el cual la aspiración ética se puede definir por tender a la vida buena, con y para los otros, en instituciones justas, lo que convertido en lenguaje pragmático equivale a cuidado de sí, cuidado de los otros y cuidado de las instituciones (Ricoeur, 2002). La primera de las aspiraciones hace referencia a la ética del autocuidado o cuidado de sí mismo, que no es egoísmo ni nada parecido, sino sencillamente estimarse lo suficiente como para tomar las riendas de la vida propia, haciéndose responsable de las decisiones libres que tomamos en relación con nuestra salud, régimen de vida y proyecto personal, incluido, como no puede ser de otra manera, el recurso a la tecnología sanitaria. En segundo lugar, nos encontramos con el cuidado del otro y de los otros, que tomamos como solicitud y respeto, que complementan la estima de uno mismo con la inestimable reciprocidad, que debe ser la base de la responsabilidad mutua y compartida, ante todo aquello que depende de la solidaridad y la colaboración de todos. El cuidado de los otros tiene dos dimensiones esenciales: cuidado de la amistad, considerada como el valor cívico por excelencia, y cuidado de los demás en el sufrimiento y la enfermedad. En tercer término, y para resumir esta ética de urgencia para la pandemia, hay que insistir en la aspiración humana de vivir en instituciones justas, único ámbito de realización de la libertad y las libertades. Introducimos ahora la necesidad de que la libertad humana se produzca en el seno de instituciones, que no son ni deben ser rígidos corsés que impidan su crítica y mejoramiento, dirigidas por un sentido de la justicia, a la que se subordina toda institución social, desde la familia al gobierno.

La aspiración a la justicia social va más allá y perfecciona el sentido espontáneo de justicia que atesora todo ser humano en su fuero interno, y lo completa con las dimensiones conmutativa $y$ distributiva de la misma. A diferencia de la conmutativa, que asegura la igualdad de derechos (isonomía) de todos los ciudadanos, la justicia distributiva se constituye en la dimensión fundamental de la ética en la época de pandemia. En la medida en que la distribución es proporcional, demanda de cada uno según su capacidad y devuelve a cada uno según su necesidad. Vivimos en sociedades como las actuales, con un sistema de reparto y distribución, que se refiere a los derechos y deberes, a los ingresos y patrimonios, a las responsabilidades y poderes, en suma, a los beneficios y cargas, entre absolutamente todos los ciudadanos, sin distinguir edad, sexo o color de su piel, o estatus socioeconómico. La lucha por la desigualdad debe figurar en primer término de la agenda de científicos y políticos. No 
hay mejor arma ni remedio contra los males humanos, sean de la naturaleza que sean, que un buen sistema de justicia social igualitaria, aplicado con imparcialidad, y que atienda también los elementos que humanizan como ninguno a lo justo y la acción política: la benevolencia general, la munificencia, y la compasión con y del sufrimiento.

\section{Conclusiones, si caben}

Nuestra contribución ha procedido a plantear someramente el problema de la pandemia que vivimos desde la perspectiva de una filosofía de la salud, tomada como la que se ocupa de la deseable y exigible competencia de todo ciudadano/a, libre e igual, que aspira a vivir una vida buena y a ser feliz en la medida de sus posibilidades, en el contexto de una coexistencia pacífica, en sociedades presididas por la justicia como norma básica de convivencia. Hemos insistido en el eje axial de la salud, que es todo aquello que nos permite ser mujeres y hombres activos, trabajadores, emprendedores, solidarios y cooperativos. La salud que quiere ser integral no sólo la proporcionan los remedios $\mathrm{y}$ medicinas, sino el hacer acopio de la energía para acometer todo lo que nos proponemos como individuos singulares, que vivimos en instituciones sociales que nos humanizan $y$ liberan, y que nos permiten la realización de los diferentes proyectos personales, en un régimen deseable de igualdad de oportunidades.

Además de lo dicho, queremos extraer un corolario, que puede parecer un estrambote, pero que no lo es, al menos en la intención de las autoras de este artículo. Buena parte de la responsabilidad de y en la toma de decisiones sobre la pandemia recae sobre los gobiernos, sobre los que se agolpan multitud de críticas desde todos los sectores de la sociedad, justas e injustas, bienintencionadas o desalmadas. A pesar de que pueda haber casos de corrupción y de mal gobierno, de pésima gestión sanitaria o epidemiológica, de adopción de medidas de emergencia equivocadas, es completamente necesario suponer buena fe, deseo de hacer las cosas lo mejor posible, y ni siquiera imaginar, ni por lo más remoto, que un gobernante pueda no querer preservar la población de su país de la enfermedad y la muerte. Esto exige, en tiempos hipercríticos, un cambio de actitud ante la política y el gobierno, que no coincide con el generalizado pesimismo actual. La actitud de benevolencia, de otorgar un margen de confianza, por parte de la ciudadanía, ante las decisiones que los gobiernos y los gobernantes se ven obligados a tomar, en condiciones muy difíciles en la mayoría de los casos, es la mejor contribución a que la situación sanitaria mejore. Todo esto no es arrojar una tabla de salvación a los gobiernos y gobernantes corruptos, sino todo lo contrario. Tratamos modestamente del rearme ético de la ciudadanía democrática, para ser, a un tiempo, crítica y constructiva.

Paralelamente, todo aquello que contribuya al restablecimiento de las actividades económicas y productivas, la vuelta a la normalidad de nuestras vidas, a la docencia, investigación y transferencia del conocimiento a la sociedad, para que lo presencial vuelva a ganar la batalla a lo virtual, sin que esto deje de ser una herramienta de gran ayuda, debe dirigir la actuación de los ciudadanos y los poderes públicos. Echamos en falta un espíritu de colaboración, de comprensión y de solidaridad con aquellos que tienen que tomar decisiones cruciales para la vida colectiva en nuestros países, los de la comunidad iberoamericana, que tanto está sufriendo los azotes de la pandemia. A buen seguro, la humanidad saldrá reforzada de esta situación de emergencia en un respecto muy concreto, en lo que concierne a una implementación de la conciencia de que sólo una respuesta global por parte de nuestra especie puede afrontar el reto del presente y los desafíos que el futuro pueda plantear. En ese frente de batalla, en esa primera línea de fuego, en la trinchera del combate, han estado, están y seguirán estando los humanistas de todos los confines del mundo conocido, y su búsqueda permanente de una norma que permita in-morar de modo más humano el planeta Tierra. 


\section{Referencias}

Álvarez Gómez, M. (2007). Teoría de la historicidad. Madrid: Síntesis.

Aranda Torres, C. (1992). ¿Qué es el reino animal del espíritu? El Basilisco (Oviedo), 2, (12) 69-74.

- (2015). Una lectura filosófica de E. A. Poe. Almería: Círculo Rojo.

Butler, J. (2020). El capitalismo tiene sus límites. Sopa de Wuhan. Madrid: ASPO.

Byung-Chul Han (2020a). La desaparición de los rituales. Una topología del presente. Barcelona: Herder.

- (2020 b). La emergencia viral y el mundo de mañana. Sopa de Wuhan. Madrid: ASPO.

Castro Orellana, R. (2008). Foucault y el cuidado de la libertad. Ética para un rostro de arena. Santiago de Chile, LOM.

Descartes, R. (2006). Las pasiones del alma (1649). Madrid: Tecnos.

Gadamer, H.-G. (1993). El estado oculto de la salud. Barcelona: Gedisa.

- (2002). Éthos y ética (1985). Los caminos de Heidegger (pp. 73-82). Barcelona: Herder.

Foucault, M. (1999). La ética del cuidado de sí como práctica de la libertad. En Estética, ética y hermenéutica. Obras esenciales III (pp. 393-415). Barcelona: Paidós.

Fuentes, C. (1999). Una globalización humana. La Reforma, México, 8 de octubre. También en: En esto creo. México: Alfaguara, 2002.

Hegel, G. W. F. (1997). Enciclopedia de las ciencias filosóficas en compendio. Para uso de sus clases (1830). Ed. R. Valls Plana. Madrid: Alianza.

Heidegger, M. (2007). La pregunta por la técnica. Barcelona: Folio.

- (2002). Serenidad (1955). Barcelona: Del Serbal.

Kant, Immanuel (2000). Crítica de la razón práctica (1788). Madrid: Alianza.

- (2007). Crítica de la razón pura (1781-1787). Ed. M. Caími. México: Colahuie

- (2006). Ideas para una historia universal en clave cosmopolita, y otros escritos sobre filosofía de la historia (1786). Madrid: Tecnos.

Ochoa Pineda, A. C. y Aranda Torres, C. J. (2019). Sexting. Un signo de identidad juvenil de la sociedad digital. Almería: Universidad de Almería.

Pita, M. (2020). ¿Y el virus qué piensa? El País, viernes 15 marzo 2020, pág. 10.

Ricoeur, P. (2002). Ética y moral (1990). En C. Gómez (ed.), Doce textos fundamentales de la ética del siglo XX (pp. 241-256). Madrid: Alianza.

Spaemann, R. (1991). Teleología natural y acción. Anuario filosófico, 1991(24), 273-288.

Tarde, G. (2001). Fragmento de historia futura (1904). Barcelona: Abraxas.

Trías, E. (1991). Lógica del límite. Barcelona: Destino.

- (2000). Los límites del mundo. Barcelona: Destino.

Žižek, S. (2020a). El coronavirus es un golpe al capitalismo a lo Kill Bill... Sopa de Wuhan. Madrid: ASPO.

- (2020b). Pandemia. La covid-19 estremece al mundo. Barcelona: Anagrama. 